\title{
Public-private partnerships needed in horticultural research and development
}

\author{
Gordon Rausser \\ Holly Ameden
}

$\nabla$

University-industry partnerships are proliferating in the United States, as public funding for high-level research continues to decline yet knowledge plays an increasingly important role in industrial processes. The horticulture industry benefits from such arrangements by influencing research directions and gaining access to innovations and complementary research in agri-cultural biotechnology. Given the nature of this industry, the obstacles to developing effective partnerships are substantial. Private horticulture institutions should form consortia of both small- and medium-sized firms, and they should understand the need for faculty and academic freedom. More enterprising members of a consortium can capitalize on the research contacts and pursue firmspecific, applied-research partnerships. Potential drawbacks are the exclusion of smaller firms and inequitable benefits-sharing within the consortia.

$\mathrm{H}$ orticultural research is conducted primarily in the public sector, with research at private institutions playing a relatively minor role. As a result, research gaps naturally emerge between the basic research generated by public institutions and the research needs of industry. One approach for reducing this gap is to form publicprivate research partnerships that harness the complementary research and academic expertise of universities with the commercialization and market- ing expertise found in industry. Such partnerships are proliferating, especially between universities and large life-sciences companies. Unfortunately, there are few concrete examples of such partnerships in agricultural biotechnology for the horticulture industry. The challenge is to adapt models of these partnerships to the research needs and structure of the horticulture industry, which produces crops such as fruits and vegetables, nuts, and nursery and ornamental crops.

The traditional research paradigm posits a one-way flow from basic science conducted in public institutions to applied research and commercialization undertaken largely by private industry. This characterization does not accurately portray current trends in research and development (R\&D).
Increasingly, public universities and private firms engage in joint research and establish interactive relationships. Several factors have contributed to this trend, including recent legislation (the Bayh-Dole Act of 1980), the restructuring of many of the larger life-sciences firms (such as Monsanto and Syngenta) and an alignment of private and public incentives to pursue long-term R\&D efforts (Rausser 1999).

The potential benefits from university-industry partnerships in the field of agricultural biotechnology are obvious. Scientific and practical knowledge can complement each other, leading to more rapid and far-reaching innovation. Universities need funding for their researchers, as well as intellectual property held by private companies and access to modern, commercially

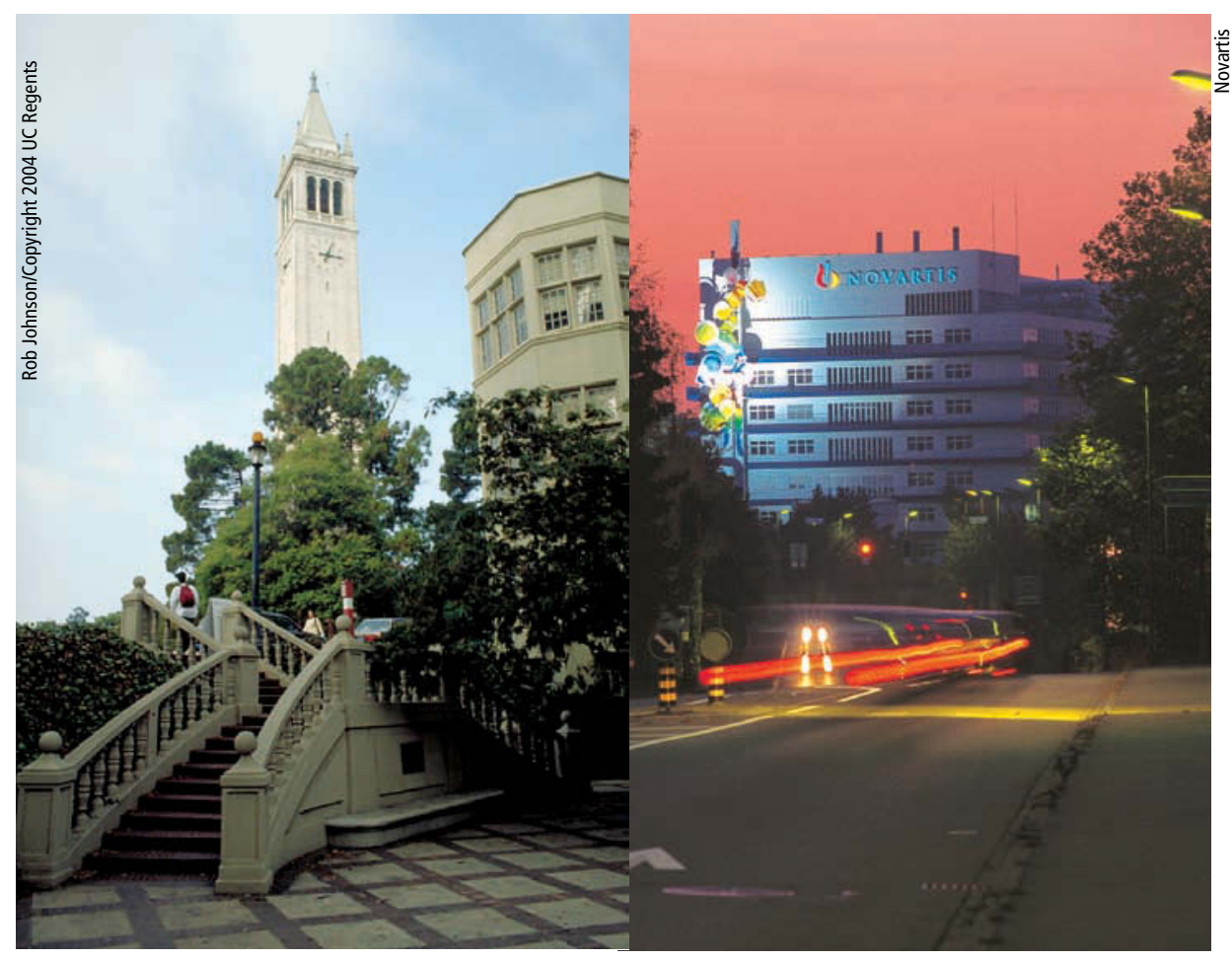

Partnerships can link university research expertise with the commercialization and marketing savvy of industry: such partnerships are proliferating in the United States. For example, in 1998 the Department of Plant and Microbial Biology at UC Berkeley,

left, entered into a 5-year, \$25 million research agreement with a multinational life-sciences company, Novartis, right (Basel, Switzerland), and its successor company, Syngenta. 
developed enabling technologies (such as gene expression profiles and genome maps) to ensure a first-rate graduate education for students. For its part, industry is interested in accessing new research and innovation, developing new products and hiring highly trained graduate students.

However, obstacles to the formation of successful agreements are significant. Both parties in a research partnership face serious risks. These risks are rooted in the conflict between a university's academic objectives and the private firm's corporate incentives. One critical risk is the potential co-opting of the academic research agenda by private interests. University researchers risk the loss of academic freedom and integrity while industry risks the loss of investment capital, privacy and proprietary information. Differences between the university's educational objectives and corporate goals, as well as differences in the cultures, institutional incentives and time frames, can lead to a clash of cultures and values. Intellectual property (IP) rights issues are also a frequent source of contention. Given these risks, both parties need to enter into carefully structured research agreements.

\section{Structuring agreements}

Most work examining research partnerships focuses either broadly, on such issues as the source of research funding, basic provisions of these agreements and associated problems and consequences (Blumenthal et al. 1996; GUIRR 1999; NAB 2001), or narrowly, on specific aspects of a particular type of agreement (NIH 1994). Although this literature is useful, it does not effectively address how to structure these public-private research partnerships. In response to this need, we have constructed templates based on the three stages of any universityindustry research partnerships, which provide a framework for characterizing their "front-end" and "back-end" options (Rausser and Ameden 2003).

University-industry research partnerships come in many forms. They may be targeted, with private firms designating specific research agendas, or they may be nontargeted. Research projects may have short or longer time horizons. Universities may enter agreements with a single private company or with groups of firms sharing a common interest (an industry consortium). Collaborations may cover a single research project or be "mega-agreements" covering a large range of interactions (examples include UC Berkeley-Novartis and Washington University, St. Louis-Pharmacia).

Because of the inherent uncertainty in the research process, research partnerships can be structured in terms of ex ante decisions (those made prior to initiating a research partnership) on the options embedded in the three stages of any agreement. These embedded options are specific decision points, such as determining which partner will control the research agenda. Universities can define policies on this option ex ante, before potential partners are approached.

Stage I: Setting the bargaining space. To start, potential research partners consider possible collaborations and associated tradeoffs. The vital aspect of this stage is determining exactly how partners will be identified and selected. Although deliberately seeking out partners rather than waiting to be filing responsibility, property and licensing rights, royalty rates and how research results will be disseminated.

Stage III: Reviewing and renewing the partnership. Finally, the outcome of the partnership is assessed, with an eye toward whether to renew the agreement. Currently, there is no standard approach for formal review of largeor small-scale agreements. To assess whether a research partnership was successful or not, interested parties must rely on the informal reviews and vague impressions of both partners along with more tangible outcomes, such as the number of patents generated by the research. A key policy challenge is the development of concrete indicators or measures of productivity for publicprivate research partnerships.

\section{Templates for partnerships}

Based on these stages of forming agreements, we have designated four groups of templates.

Strategic partnerships involve comprehensive, multiyear commitments between a university, or an academic department in a university, and a large company, with both partners

\section{Differences between the university's educational objectives and corporate goals can lead to a clash of cultures and values.}

approached with a proposal requires more effort upfront, it can substantially broaden the set of choices. For example, the public partner could elicit competitive bids from multiple private partners rather than just accepting or rejecting a single proposal.

Stage II: Negotiating the agreement. Next, the agreement is negotiated and may or may not involve a formal contract. Front-end options determine the nature and scope of the research activities that the partnership will undertake, while back-end options determine how any benefits generated by the partnership will be distributed and how knowledge assets such as patents and commercial products are disseminated. Decisions in the front-end include specifying the research agenda, asset contributions, governance structures and scale of operations. Back-end options include designating patent- dedicating significant assets. Formal procedures for determining research agendas and control of back-end assets are specified. Given their size, these agreements tend to come under significant scrutiny and often external review.

One such agreement was the 5-year, $\$ 25$ million research agreement between Novartis (and its successor company, Syngenta) and UC Berkeley's Department of Plant and Microbial Biology. The relationship, which generated approximately 20 innovations, was the subject of an internal campus review by the office of the Vice Chancellor for Research. The review found the research had not been skewed toward applied biotech research as feared and that graduate students were the primary beneficiaries.

Research unit/center partnerships usually also involve the dedication of significant resources. Instead of involv- 
ing existing academic departments, however, these research units are set up separately, allowing more distance between the partnership and the academic community at the university. Such partnerships may be linked to a single company, commodity group or companies that provide some or all of the financial resources for the research center. For example, the Seed Biotechnology Center at UC Davis is a partnership between the College of Agricultural and Environmental Sciences and the California seed industry. The College provides research space and faculty time, while the industry funds additional research and programmatic personnel. Specific research projects are funded through diverse grants and contracts with both public agencies and private sources.

Sponsored projects are small to large commitments with a specific research agenda designated at the outset. As with strategic partnerships, either partner may approach the other, but instead of defining a governing structure for selecting research directions, specific research projects of particular duration and budget are proposed. Depending on the nature of the bargaining space (e.g., private partner proposes project versus the university approaches private partner with research needs), the university's options on the front-end can be more restricted. Sponsored projects may act as testing grounds for relationships and serve as precursors for more far-reaching strategic partnerships. Through more than 50 commissions and other organizations, industry groups provided more than $\$ 22$ million to support public research programs at UC Davis last year, a large fraction of that in the plant sciences.

Informal arrangements are generally the initial mode of contact between university and industry partners. Through networking with contacts, industry scientists identify valuable university counterparts and vice versa, and set up simple arrangements involving minimal transaction costs. These agreements can either be transparent, public collaborations or may involve more indirect arrangements such as corporate gifts that are not tied

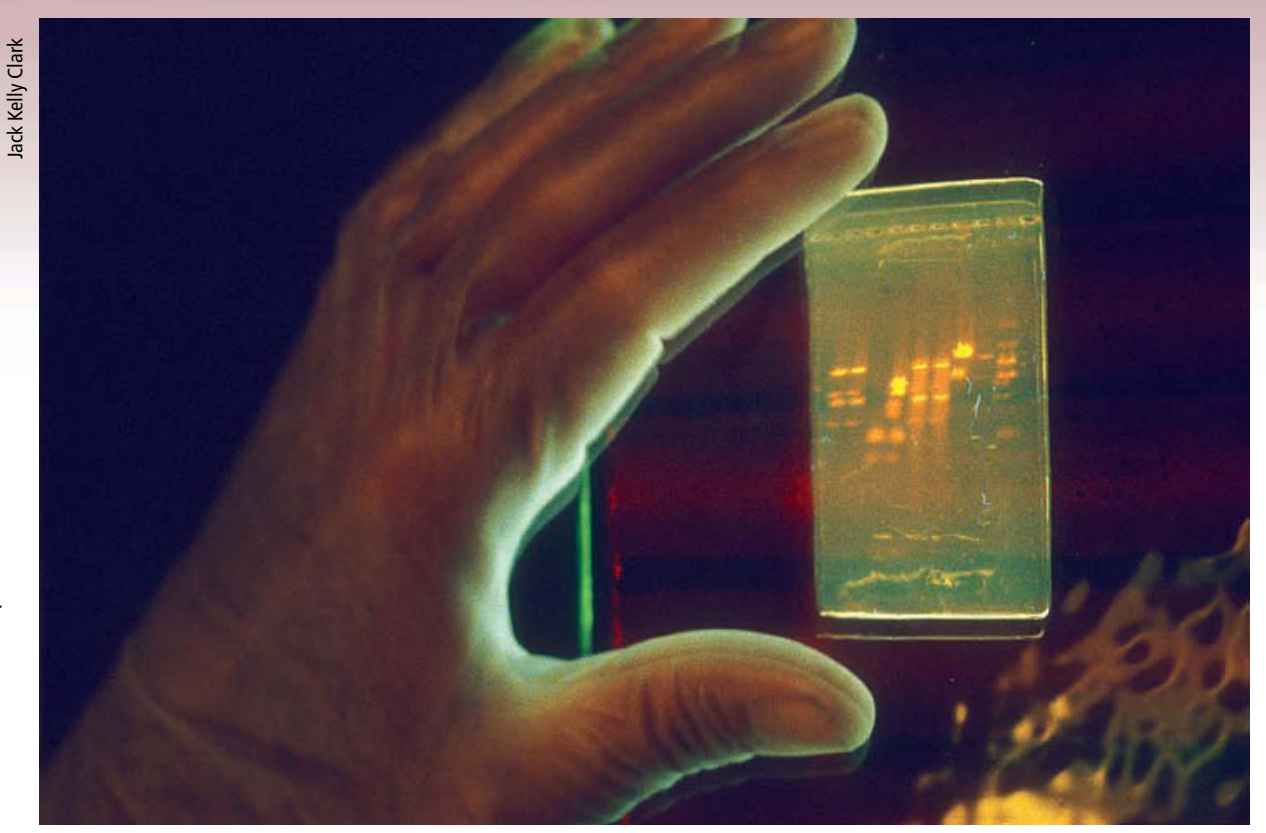

Smaller firms have the capacity to rapidly apply new technology, but when it comes to techniques involving recombinant DNA they often do not have the assets to develop commercially viable products. Partnerships can help by sharing the costs of research, development and testing that are needed to bring a genetically engineered product to market. Above, gel is used to separate DNA molecules according to their length.

to any specific collaboration or in-kind donations of services, equipment or materials. This category would include pesticides or tractors donated for a field trial and technical expertise for setting up a research program.

\section{Horticultural industry and research}

The horticultural research industry is composed primarily of small to medium enterprises (Dixon 1998) with small markets for individual products. Because of their relatively smaller size, these firms are able to rapidly apply new knowledge and technology. However, when it comes to genetically engineered crops, the smaller firms generally do not have the assets to develop new products.

Research funds in horticulture come mainly from the public sector (Sansavini 1998; Dixon 1998). The reluctance of major biotechnology R\&D companies to dedicate funds to horticultural research is, in part, because technological advances in horticulture are not viewed as "low-hanging fruit." The commercial value is not nearly as attractive as for annual agronomic crops grown on large acreages. In addition, consumer acceptance of genetically modified foods is considered a major obstacle to the adoption and commercialization of agricultural biotechnology. Current biotech research focuses on reducing the environmental impacts of horticultural production, food safety, product quality and new-product development (Robitaille 1998).

Public-private research partnerships could greatly benefit the horticulture industry, and domestic and international research partnerships in horticulture are considered especially important for developing economies (Robitaille 1998). Dixon (1998) notes that successful entrepreneurs in horticulture maintain a continuous dialogue with scientists; partnerships are one approach for guaranteeing this dialogue. Dixon also notes that linkages between research and industry (public and private relationships) have improved "where levy funding systems have been established to support scientific endeavors." In other words, more formal financial arrangements between partners are likely to yield the best exchange.

\section{Strategies for horticulture R\&D}

The most relevant partnership model for the horticulture industry is that of less formal, single or multipleproject partnerships (sponsored project and informal arrangements). In pursuing these partnerships, the implications of all three stages of the partnership should be considered ex ante.

In Stage I (setting the bargaining space), private horticulture institutions 
seek to align research incentives and form consortia of small and medium firms with parallel research interests to concentrate intellectual and financial resources. These consortia are organized by crop or pest type (or other research interests) to facilitate networking, identify key researchers at public institutions and propose specific research projects. (A proportional-contribution/equal-sharing scheme between consortia members is likely to be the most effective self-governing approach given the public nature of research leads and outcomes.)

The university should accept or reject these proposals based on the research synergy and embedded options. Although all universities share a common set of core principles that guide their decisions, different institutions emphasize different objectives; the private partner should consider the university's research climate when considering research partners.

In Stage II (negotiating the contract), the private partner considers the type of research to pursue in the partnership. Given the nature of research objectives at universities, the horticulture industry partner should propose research projects that are more basic, have longer time frames and are not adequately addressed by current private research efforts. These partnerships are more likely to be successfully negotiated if the industry partner understands, ex ante, the need for faculty and academic freedom. On the backend, university guidelines and policy usually constrain its researchers to specific conditions for patenting research, and licensing and disseminating results (publication delays). Although there is some variation, these constraints are fairly common at universities.

Stage III (reviewing the partnership) is best accomplished if specific goals or benchmarks are incorporated into the initial agreement. This gives both sides criteria to judge whether the partnership is achieving its goals and justifies renewal.

\section{Consortia benefits and risks}

Both partners should establish links so that industry can more effectively

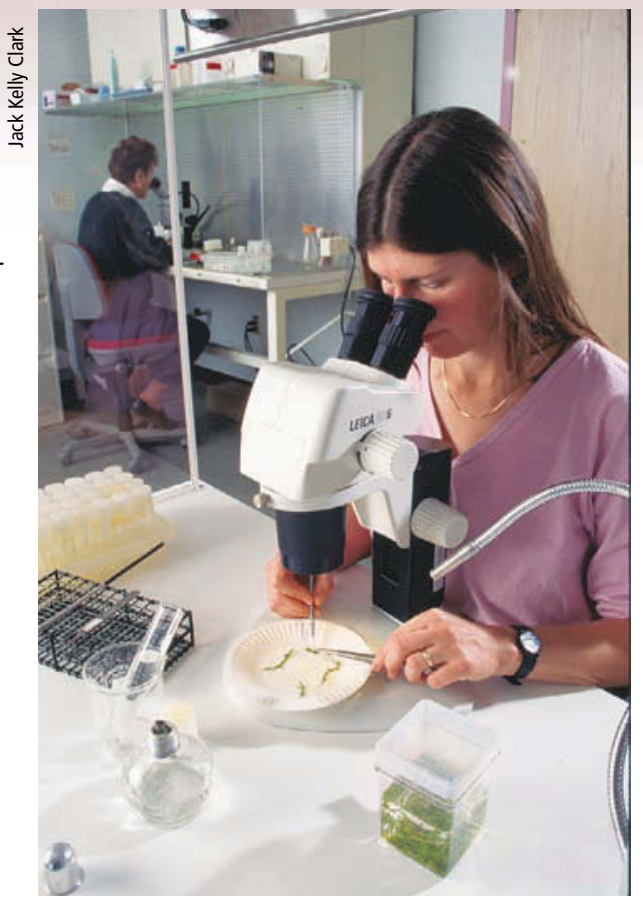

The time and effort involved in negotiating public-private research partnerships is substantial, but such arrangements can be fruitful for both parties. Above, a UC scientist uses tissue culture to propagate grapes in the laboratory.

utilize public research and universities can secure access to research funding and cutting-edge enabling technologies. These collaborations can serve as stepping-stones to more formal, longterm agreements. Alternatively, once initial consortia-university research partnerships are established, more enterprising members of the consortia can capitalize on the research contacts and pursue firm-specific, applied-research partnerships.

The primary obstacle to forming research partnerships is high transaction costs. The process of identifying appropriate researchers as potential partners can involve significant search costs. And once potential partners have been selected, the time and effort involved in negotiating a research agreement, especially given the differing objectives of public versus private institutions, can be substantial. The consortium approach is a strategy for sharing these costs. If the consortia are not well structured, however, reduced external transaction costs may be replaced by higher internal costs of organizing and running the consortia. Inequitable benefits-sharing within a consortium may also be a source of conflict. And although this approach is intended to serve the needs of medium- to smallersized firms, the smallest enterprises may still be excluded (especially in subsequent partnerships).

\section{G. Rausser is Robert Gordon Sproul} Distinguished Professor, and H. Ameden is Ph.D. Candidate, Department of Agricultural and Resource Economics, UC Berkeley. The UC Berkeley-Novartis agreement was designed and implemented while Professor Rausser was Dean of the College of Natural Resources at UC Berkeley.

\section{References}

Blumenthal D, Causino N, Campbell E, Louis KS. 1996. Relationships between academic institutions and industry in the life sciences: An industry survey. New Eng J Med 334:368-73.

Dixon GR. 1998. Market-led horticultural research: Does this provide what the industry needs? World Conference on Horticultural Research, June 17-20, Rome, Italy. http:// pop.agrsci.unibo.it/wchr/wc3/dixon.html.

[GUIRR] Government-University-Industry Research Roundtable. 1999. Overcoming Barriers to Collaborative Research. GUIRR workshop, March 23-4, 1998. Irvine, CA. Washington, DC: Nat Acad Pr. 60 p. www7. nationalacademies.org/guirr/PUBLICATIONS. html.

[NAB] National Alliance of Business. 2001. Research Collaboration Initiative Business-Higher Education Forum: Draft Final Report. www.nab.com.

[NIH] National Institutes of Health. 1994. Developing sponsored research agreements: Considerations for recipients of $\mathrm{NIH}$ research. NIH Guide 23(25). http://ott.od.nih. gov/newpages/text-com.htm.

Rausser G. 1999. Private/public research: Knowledge assets and future scenarios. Am J Ag Econ 81(5):1011-27.

Rausser G, Ameden H. 2003. Structuring public-private research agreements: The critical role of control premiums. Draft working paper. Center for Studies in Higher Education, UC Berkeley.

Robitaille HA. 1998. Needs and expectations of the horticulture-related industry. World Conference on Horticultural Research, June 17-20, Rome, Italy. http://pop.agrsci. unibo.it/wchr/wc3/robitaille.html.

Sansavini S. 1998. Key issues facing research in horticulture: An overview, prospects, and the role of cooperation. World Conference on Horticultural Research, June 17-20, Rome, Italy. http://pop.agrsci.unibo. it/ wchr/wc5/sansavin.html. 